\title{
PENGARUH KUALITAS PELAYANAN B2B PERBANKAN SYARIAH DAN CULTURAL FIT PADA KEPUASAN, LOYALITAS, DAN REKOMENDASI POSITIF
}

\author{
Ekawati Rahayu Ningsih, Tulus Haryono, \\ Hunik Sri Runing Sawitri, Mugi Harsono \\ Program Doktor Ilmu Ekonomi dan Bisnis (PDIE) \\ Universitas Sebelas Maret (UNS) \\ Surakarta \\ Email : Safarajuara@gmail.com
}

Abstrak

Artikel ini bertujuan untuk mengatasi kesenjangan tentang teori dasar tentang kualitas layanan dalam hubungan pemasaran. Artikel ini hendak menguji pengaruh strategi peningkatan kualitas pelayanan $B 2 B$ perbankan syariah dan culture fit terhadap kepuasan konsumen, loyalitas dan rekomendasi positif. Kajian ini juga berusaha mendemonstrasikan keterkaitan antara variabelvariabel. Sampel yang diambil 200 responden yang terdiri atas: pemilik usaha, pemimpin organisasi/perusahaan dan manajer keuangan yang memanfaatkan transaksi elektronik dari BSM Kudus dan Pati, baik sebagai kreditur, debitur maupun pengguna layanan BSM lainnya. Hasil analisis koefisien path menunjukkan bahwa dimensi empati, tangible, keandalan, kepatuhan, dan culture fit berpengaruh secara langsung maupun tidak lengsung terhadap kesetiaan nasabah.

Kata Kunci: Pemasaran, Layanan, Budaya.

Abstract

THE INFLUENCE OF SERVICE QUALITY OF B2B SHARIA BANKING AND CULTURE FIT TOWARD CUSTOMER SATISFACTION, LOYALTY AND POSITIVE 
RECOMMENDATIONS. This goal of this article is to overcome the research gap by developing the basic theory of the service quality in relationship marketing. This article examines effect of strategy of improving service qaulity of $B 2 B$ sharia banking and culture fit toward customer satisfaction, loyalty and positive recommendation. The study also seeks to demonstrate the interdependence between variables. Convenience samples are 200 respondents: business owners, heads of organizations/companies and financial managers who make use of electronic transactions of BSM Kudus and Pati, whether as a creditor, debitor or other services of BSM. Result of path coefficient analysis shows that the dimensions of empathy, tangibles, reliability, compliance and cultural fit directly or indirectly have effect on loyalty.

Keywords: Marketing, Service, Culture

\section{A. Pendahuluan}

Pertumbuhan dan perkembangan perbankan syariah di Indonesia dalam tujuh tahun terakhir menunjukkan hasil yang sangat menggembirakan. Hal ini dibuktikan dengan pertambahan jumlah bank syariah telah mencapai 35 unit terdiri atas 11 Bank Umum Syariah (BUS) dan 24 Unit Usaha Syariah (UUS). Selain itu, jumlah Bank Perkreditan Rakyat Syariah (BPRS) telah mencapai 155 unit pada periode yang sama (BI, Statistik Perbankan Syariah, Januari 2012). Total jaringan kantor sebanyak 2188 dan tersebar di seluruh wilayah Indonesia pada akhir bulan oktober 2012 (Outlook Perbankan Syariah Bank Indonesia, 2013). Sedangkan secara geografis, sebaran jaringan kantor perbankan syariah saat ini telah menjangkau masyarakat lebih dari 120 kabupaten/kota di 33 propinsi di Indonesia.

Dari akhir tahun 2011 sampai dengan akhir tahun 2012 perkembangan aset perbankan syariah meningkat signifikan sebesar lebih dari $33.37 \%$. Penghimpunan dana dan pembiayaan mencapai peningkatan sebesar $41.84 \%$ dan $22.74 \%$. Jika dilihat dari rasio pembiayaan yang disalurkan dengan besarnya dana pihak ketiga yang dinyatakan dengan nilai Financing to Deposit Ratio (FDR), maka bank syariah memiliki rata-rata FDR sebesar $97.65 \%$ 
(BI, Statistik Perbankan Syariah, Januari 2012). Kondisi ini juga di perkuat oleh fundamental ekonomi Indonesia yang semakin kokoh, proses pemulihan ekonomi global yang semakin baik di tahun 2012, dan dukungan legal formal kelembagaan maupun perpajakan yang lebih kondusif, sehingga mempengaruhi dan mendorong peningkatan kinerja perbankan syariah (Biro Humas BI, 2-12-2012).

Selain kondisi tersebut diatas, peningkatan kepercayaan dan minat masyarakat terhadap bank syariah juga dikarenakan beberapa faktor. Pertama, mayoritas penduduk Indonesia adalah muslim. Kedua, masyarakat Indonesia sangat menjunjung tinggi nilai-nilai etika dan budaya timur yang bercirikan kebersamaan dan tolongmenolong. Ketiga, survei Bank Indonesia menunjukkan bahwa tingkat penerimaan masyarakat di Pulau Jawa terhadap keberadaan sistem perbankan syariah masih sangat tinggi (Majalah Sharing, 2011). Ke-empat, kurang lebih 4.000 responden rasional yang tersebar di empat provinsi di Jawa, lebih dari 95\% berpendapat bahwa sistem perbankan syariah sangat penting untuk mendukung kelancaran transaksi ekonomi, karena terbukti kebal dari penyakit negative spread (Majalah Sharing, 2009). Kelima, pesatnya perkembangan teknologi informasi dan komunikasi dalam dekade terakhir, membuat Internet dan World Wide Web menjadi alat penting dalam bisnis global dan berhasil merevolusi perjalanan industri perbankan syariah secara signifikan.

Masukan penting bagi bank-bank syariah saat ini antara lain adalah, bahwa masyarakat non-nasabah bank syariah yang diberi penjelasan tentang sistem, produk dan jasa serta kehalalan bank syariah mempunyai kecenderungan kuat untuk memilih bank syariah, tetapi sebaliknya nasabah yang telah menggunakan jasa bank syariah, sebagian memiliki kecenderungan untuk berhenti jadi nasabah, dikarenakan antara lain karena kualitas pelayanan yang buruk ataupun karena kecurigaan dan keragu-raguan akan konsistensi penerapan prinsip syariah (Harian Republika, 2010). Oleh karena itu kualitas pelayanan selalu menjadi isu strategis di sektor perbankan syariah dan jasa keuangan lainnya (Lewis \& 
Smith, 1994).

Kualitas pelayanan perbankan syariah menjadi salah satu faktor pendahulu dari kepuasan nasabah dan keunggulan kompetitif (Lewis \& Smith, 1994; Parasuraman, A., Zeithaml, A.V. and Berry, L.L., 1985; Zeithaml. A.V, Berry.L.L, and Parasuraman. 1990). Kualitas pelayanan sangat penting dalam mendukung pengembangan hubungan jangka panjang antara perbankan dengan nasabahnya. Karena hal tersebut, maka tantangan terbesar bagi perbankan syariah saat ini adalah bagaimana upaya menciptakan kepuasan nasabah, baik nasabah individual maupun nasabah korporasi, baik dalam pasar domestik maupun pasar global, baik nasabah dengan skala usaha kecil, menengah ataupun besar.

Apapun konsep produk yang dikembangkan perbankan syariah, tidak akan dapat berhasil tanpa di iringi penambahan jasa layanan yang baik. Hal ini juga selaras dengan strategi yang digambarkan Kotler (2004), bahwa tingkatan produk pada awalnya hanya lebih menekankan kepada fungsi produk saja, tetapi dalam pengembangannya harus memperhatikan aspekaspek lain, yaitu bagaimana kualitas pelayanan berpengaruh pada tingkat kepuasan di dalam hubungan pemasaran. Kotler (2004) juga mengindikasikan bahwa faktor utama untuk mempengaruhi preferensi merek dan intensitas pembelian kembali konsumen adalah kepuasan pelanggan dan nilai yang dirasakan.

Oleh karena itu penelitian ini mengambil tema tentang pengaruh kualitas pelayanan B2B perbankan syariah dan kecocokan budaya nasabah bisnis terhadap kepuasan, loyalitas dan rekomendasi positif. Beberapa alasan yang mendasari pemikiran ini adalah: pertama, perbankan syariah tidak hanya melayani pasar konsumen, tetapi juga pasar industri/bisnis (Rajiv dan James Brown, 1998). Kedua, penelitian empiris tentang pengaruh kualitas pelayanan elektronik perbankan syariah terhadap kepuasan nasabah memang telah banyak dilakukan, namun biasanya hanya berfokus pada nasabah individual, sedangkan terhadap nasabah industri/bisnis belum banyak dilakukan (Zeithaml.A.V, Berry.L.L, 
and Parasuraman. 1990; Woo dan Ennew, 2005). Ketiga, terdapat beberapa kesenjangan (gap) baik teori maupun hasil penelitian yang membuka peluang bagi peneliti selanjutnya untuk meneliti dan menguji kembali validitas hasil temuan tentang pengaruh kualitas pelayanan B2B perbankan syariah dan kecocokan budaya nasabah bisnis pada kepuasan, loyalitas dan rekomendasi positif dalam konteks pemasaran hubungan.

Terdapat tiga kesenjangan teori dan dua kesenjangan penelitian terdahulu, yang bisa ditindaklanjuti dalam penelitian berikutnya. Tiga kesenjangan teori meliputi: pertama, tidak adanya konsensus yang jelas (multifacet) di antara para peneliti terdahulu tentang bagaimana pengukuran dampak keseluruhan praktik pelayanan B2B dan kualitasnya dalam pemasaran hubungan (Guo, Duff dan Hair, 2007). Penggunaan teori SERVQUAL (Parasuraman et al., 1985) untuk menganalisis kualitas pelayanan B2B dianggap kurang tepat (Gounaris and Venetis, 2002). Tetapi Lassar et al., (2000) mengatakan bahwa teori SERVQUAL (Parasuraman et al., 1985) bisa digabungkan dan dikelola bersama dengan dimensi kualitas teknis dan dimensi kualitas fungsional dari Gronroos (1984) untuk menganalisis kualitas pelayanan B2B perbankan syariah. Langkah penggabungan teori sebagaimana di katakan Lassar et al. (2005) juga diperkuat dalam penelitian Caceres dan Paparoidamis (2005). Kedua, hasil analisis Caceres dan Paparoidamis (2005) menunjukkan bahwa variabel kepuasan merupakan variabel mediator antara persepsi kualitas pelayanan B2B dengan loyalitas, tetapi hasil analisis Rauyruen, P and Miller, K.E. (2009) menunjukkan bahwa variabel persepsi kualitas pelayanan B2B bisa berpengaruh langsung pada sikap loyal dan intensitas pembelian kembali pelanggan. Ketiga, variabel kepuasan bisa dipengaruhi oleh cultural fit (Guo dan Duff, 2007; Vatanasakdakul, Ramburuth, Dambra 2010; Lele, Milind, Sheth, Jagdis, 1988; Avery, Baradwaj, Singer, 2008). Lele, Milind, Sheth, Jagdis, 1988 menunjukkan bahwa faktor-faktor budaya dasar dari Hofstede (1991) mempengaruhi dan memoderasi antara desain kualitas pelayanan dengan kepuasan pelanggan tetapi 
Avery, Baradwaj, Singer (2008) menunjukkan bahwa tidak semua faktor dari ke empat faktor budaya Hofstede (1991) berpengaruh terhadap pemahaman, kepuasan dan penerimaan atribut dari berbagai desain spesifik situs web bank online.

Oleh karena itu, dalam penelitian ini akan menguji kembali pengaruh faktor-faktor cultural fit sebagaimana yang dilakukan Vatanasakdakul, Ramburuth, Dambra (2010). Hal ini sejalan dengan apa yang disarankan Webster (1992) dan Achrol (1997) agar peneliti berikutnya mengkaji dan menganalisis kembali secara mendalam tentang desain kualitas pelayanan B2B untuk menciptakan kepuasan nasabah bisnis perbankan pada budaya yang berbeda, khususnya di negara-negara berkembang seperti Indonesia.

Dua kesenjangan penelitian meliputi: pertama, sejauh yang teramati, penelitian yang berfokus pada kualitas pelayanan berbasis pada business-to-business (B2B) perbankan syariah di Indonesia masih sangat terbatas. Sedangkan perbankan syariah juga merupakan salah satu lembaga financial intermediary terpenting di Indonesia (Susilo, Triandaru, dan Budi, 2000). Beberapa peneliti biasanya hanya memfokuskan pada bagaimana melayani nasabah individual, sedangkan pelayanan terhadap nasabah bisnis tidak diperhitungkan. Padahal dari masing-masing jenis nasabah memiliki perbedaan karakteristik yang mempengaruhi persepsi dan tingkat kepuasan yang dirasakan. Kedua, kebanyakan peneliti mengukur kepuasan pelanggan bisnis biasanya hanya terbatas pada pengukuran sikap loyal dengan menggunakan data sekunder dalam penelitian kuantitatif, yaitu di peroleh dengan cara menyebarkan instrumen kuesioner. Padahal kepuasan pelanggan tidak hanya terbatas pada sikap loyal tetapi juga berupa niat membeli kembali ataupun rekomendasi positif pada pelanggan lainnya (Cáceres dan Paparoidamis, 2005). Sikap dan perilaku pada pelanggan B2B sulit untuk diukur secara tepat dan bersifat fluktuatif, maka penelitian selanjutnya diusulkan untuk mempertimbangkan dan mengkombinasikan antara data sekunder dan data primer dalam tahapan penelitian longitudinal agar hasil temuan lebih valid dan 
reliabel (Cáceres dan Paparoidamis, 2005; Laroche, 2004)

Tujuan penting dari penelitian ini adalah: pertama, untuk mengatasi kesenjangan penelitian dengan cara mengembangkan teori dasar kualitas pelayanan dalam pemasaran hubungan dari Gronroos (1998). Kedua, membentuk dasar teoritis strategi peningkatan kualitas hubungan antara penyedia layanan B2B perbankan syariah dan kococokan budaya nasabah bisnis terhadap kepuasan, loyalitas dan rekomendasi positif. Penelitian ini juga berupaya untuk menunjukkan adanya saling ketergantungan antar variabel tersebut. Dan pada tingkat yang lebih tinggi, menunjukkan pentingnya hubungan antar variabel dalam membentuk kepuasan, loyalitas dan terciptanya rekomendasi positif nasabah bisnis.

Cáceres dan Paparoidamis (2005) menyarankan agar penelitian di masa mendatang mengembangkan hal-hal sebagai berikut: pertama, sifat data yang diambil tidak hanya sekunder tetapi juga data primer. Kedua, agar perbedaan budaya pelanggan bisnis dari berbagai latar belakang sosial digunakan sebagai variabel pengukur yang mempengaruhi kepuasan pelanggan dalam pemberian pelayanan, karena perbedaan budaya dapat mengakibatkan tinggi rendahnya tingkat kepuasan sebagaimana saran Webster (1992) dan Achrol (1997); Guo dan Duff, 2007; Vatanasakdakul, Dambra, Ramburuth, 2010; Lele, Milind, Sheth, Jagdis, 1988; Avery, Baradwaj, Singer, 2008. Ketiga, agar peneliti selanjutnya memperpanjang temuan dengan mempertimbangkan dua jenis variabel yaitu loyalitas dan rekomendasi positif sebagaimana juga yang diusulkan oleh Parasuraman et al (1991), Reichheld dan Sasser (1990).

Berdasarkan lima faktor kesenjangan yang teridentifikasi, tujuan penelitian, dan saran dari peneliti terdahulu, maka penelitian ini dilakukan dalam upaya mengatasi lima kesenjangan tersebut dengan tiga cara yaitu: pertama, mengkaji teori dan konsep dasar tentang terbentuknya persepsi kualitas layanan B2B dalam hubungan pemasaran dan mengidentifikasi dimensi-

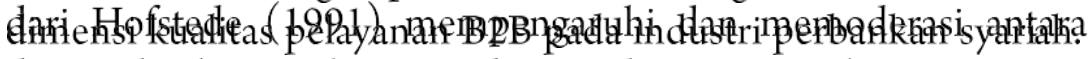
desain kualitas pelayanan dengan kepuasan pelanggan tetapi 
Konseptual model yang disajikan dalam penelitian ini berawal dari kerangka teori Gronroos (1998) tentang kualitas pelayanan terdiri dari dua aspek yaitu kualitas fungsional (bagaimana fungsi proses pelayanan) dan kualitas teknis (bagaimana proses teknis pelayanan).

Gronroos (1993) menyarankan bahwa dalam model pengukuran yang digunakan untuk menilai persepsi pelanggan harus bersifat dinamis, karena persepsi citra bisa berubah dari waktu ke waktu tergantung pada persepsi kualitas pelanggan. Oleh karena itu model pengukuran kualitas pelayanan (Perceived Service Quality) dari Grönroos $(1983,1984)$ hanya membantu peneliti dalam memahami konsep dasar tentang kualitas pelayanan B2B, sedangkan untuk model operasional, kualitas pelayanan dikembangkan dengan memasukkan semua bentuk faktor persepsi pelanggan terhadap kualitas layanan B2B industri perbankan syariah, sebagaimana yang di kemukakan Lassar et al. (2000) yang mengatakan bahwa teori SERVQUAL dari Parasuraman et al (1985) bisa digabungkan dan dikelola bersama dengan dimensi kualitas teknis dan dimensi kualitas fungsional dari Gronroos (1984) dalam menganalisis kualitas pelayanan B2B perbankan syariah. Maka, operasional model dalam penelitian ini menggabungkan tiga model teori yaitu: pertama, teori Perceived Service Quality dari Gronroos $(1983,1984)$ dikategorikan sebagai orde tertinggi, terdiri dari dua dimensi yaitu: kualitas tehnik dan kualitas fungsional. Model CARTER dari Othman dan Owen (2001) terdiri dari enam dimensi sebagai sub orde kualitas pelayanan fungsional dan model Bank Service Quality (BSQ) dari Guo, Duff dan Hair (2007) terdiri dari tiga dimensi sebagai sub orde kualitas pelayanan teknis. Semua dimensi dikumpulkan dan dievaluasi sebagai saluran komposit tunggal (Cáceres dan Paparoidamis, 2005).

Kedua, mengidentifikasi beberapa dimensi cultural fit nasabah bisnis perbankan syariah yang berpengaruh pada kepuasan, loyalitas dan rekomendasi positif dengan menggunakan cara sebagaimana yang dilakukan oleh Savanik, John dan Prem, 2010 untuk membangun kerangka konseptual dan bertujuan 
menyatukan berbagai variabel relasional yang sering digunakan dalam literatur hubungan pemasaran. Ketiga, penelitian ini menguji secara empiris atas model yang telah dirumuskan, untuk menetapkan pengaruh variabel kualitas pelayanan B2B perbankan syariah dan variabel cultural fit nasabah bisnis terhadap variabel kepuasan, loyalitas dan rekomendasi positif. Karena tujuan dalam penelitian ini adalah menguji model berbasis teori, maka penelitian ini menggunakan tehnik analisis Structural Equation Modelling (SEM). Penggunaan SEM ini sekaligus diharapkan bisa mengatasi kelima kesenjangan yang teridentifikasi.

Yang membedakan antara penelitian ini dari penelitian sebelumnya adalah pertama, dalam operasionalisasi modelnya mengembangkan teori Perceived Service Quality Grönroos (1983, 1984) sebagai orde tertinggi dan menggabungkannya dengan teori SERVQUAL yang dikenal dengan model CARTER dari Othman dan Owen (2001) terdiri dari enam dimensi sebagai sub orde kualitas pelayanan fungsional dengan model BSQ dari Guo, Duff dan Hair (2007) terdiri dari tiga dimensi sebagai sub orde kualitas pelayanan teknis. Kedua, variabel budaya yang dimaksud dalam penelitian ini adalah cultural fit atau kecocokan budaya nasabah bisnis perbankan syariah. Ketiga, menguji secara bersama-sama variabel kualitas pelayanan dan cultural fit nasabah bisnis perbankan syariah terhadap variabel kepuasan, loyalitas dan rekomendasi positif. Operasionalisasi model sebagaimana diatas, sepanjang yang teramati belum pernah dilakukan, sehingga hal ini merupakan salah satu keunikan penelitian ini dibandingkan dengan penelitian sebelumnya.

Manfaat teoritis dalam penelitian ini adalah sebagai berikut: pertama, pengembangan operasionalisasi teori kualitas pelayanan dalam area pemasaran hubungan yang menggabungkan tiga model, yaitu model Gronroos $(1983 ; 1984)$ model CARTER (Othman dan Owen, 2001), model CBSQ (Guo, Duff dan Hair, 2007), diharapkan dapat memperkuat kemampuan teori tersebut dari Hofstede (1991) mempengaruhi dan memoderasi antara desain kualitas pelayanan dengan kepuasan pelanggan tetapi 
bahkan mungkin sampai pada sikap loyal dan rekomendasi positif nasabah bisnis. Kedua, operasionalisasi dimensi-dimensi cultural fit nasabah bisnis yang mempengaruhi variabel kepuasan, loyal dan rekomendasi positif diharapkan dapat memberikan kontribusi signifikan terhadap pengembangan konsep kualitas pelayanan B2B perbankan syariah.

Sedangkan manfaat praktisnya adalah: pertama, hasil analisis penelitian diharapkan dapat dijadikan sebagai sumber informasi bagi pihak perbankan syariah tentang pengaruh kualitas pelayanan B2B perbankan syariah dan latar belakang cultural fit nasabah bisnis terhadap kepuasan, loyalitas dan rekomendasi positif. Kedua, bagi peneliti yang tertarik pada kajian ini, hasil penelitian bisa dipakai sebagai acuan primer, mengingat belum banyak penelitian yang berfokus pada kualitas pelayanan dalam konteks kualitas layanan B2B perbankan syariah.

\section{B. Pembahasan}

Kajian ini bertujuan untuk menguji hipotesis yang menjelaskan bentuk hubungan sebab akibat antar variabel bebas dengan variabel terikat, sedangkan metode analisis datanya menggunakan analisis deskriptif dan analisis kuantitatif.

\section{Metode Penelitian}

\section{a. Populasi, Sampel dan Teknik Pengambilan Sampel}

Populasi dalam penelitian ini adalah semua nasabah bisnis (priority) BSM Cabang Kudus dan Pati. Sampelnya meliputi: pemilik usaha (besar, menengah, kecil), pimpinan/ manajer organisasi/perusahaan baik BUMN, nirlaba ataupun swasta, dan manajer keuangan yang pernah melakukan transaksi elektronik dengan BSM Cabang Kudus dan Pati, baik posisinya sebagai kreditur, debitur ataupun pengguna jasa lain BSM. Teknik pengambilan sampelnya menggunakan teknik convenience sampling.

\section{b. Identifikasi Variabel}

Variabel independen meliputi: kualitas pelayanan tehnik, 
kualitas pelayanan fungsional dan kecocokan budaya. Sedangkan variabel dependen meliputi: kepuasan, loyalitas dan rekomendasi positif.

\section{c. Definisi Operasional dan Pengukuran Variabel}

Variabel pembentuk model yang akan di kembangkan dalam penelitian ini adalah sebagai berikut: pertama, variabel kualitas pelayanan tehnik terdiri dari dimensi komunikasi, teknologi dan akses sebagaimana yang dikembangkan Caceres dan Paparoidamis (2005); Guo dan Duff (2007). Kedua, kualitas pelayanan fungsional terdiri dari: compliance, assurance, reliability, tangibles, empathy, responsiveness sebagaimana dikembangkan Othman dan Owen (2001). Ketiga, kecocokan budaya (cultural fit), berasal dari teori kecocokan ( fit) dan teori budaya nasional yang kemudian diterapkan untuk penelitian adopsi teknologi informasi (Bahee 1992; Henderson dan Venkatraman 1999; Venkatraman 1989, Venkatraman dan Camillus 1984). Hal ini merupakan usaha dan

dari Hofstede (1991) mempengaruhi dan memoderasi antara desain kualitas pelayanan dengan kepuasan pelanggan tetapi 
cara terbaik membentuk strategi bisnis dengan mempertimbangkan komponen organisasi yang harus cocok antara satu sama lain untuk menghasilkan kinerja yang optimal (Donaldson 2001; Drazin dan Van de Ven, 1985; Ginsberg dan Venkatraman, 1985; Venkatraman, 1989). Item-item kecocokan budaya dalam studi Savanik, John, dan Prem (2010) yang digunakan dalam penelitian ini meliputi: hubungan personal dan koneksi yang baik dengan bank/staf bank syariah, komunikasi vis a vis dalam proses membangun kepercayaan, memiliki tujuan yang jelas dan terukur dalam berhubungan dengan perbankan syariah, mampu beradaptasi dengan teknologi informasi dan berbahasa Inggris, hubungan personal dan koneksi yang baik dengan bank/staf bank syariah. Keempat, kepuasan meliputi: pelayanan yang disediakan berkualitas unggul dan mempunyai nilai kompetitif, pelayanan yang disediakan sangat bagus dan memuaskan, pengalaman sama baiknya dengan yang dirasakan selama pelayanan, pelayanan dilakukan dengan benar pada saat pertama maupun berikutnya. Kelima, loyalitas meliputi: niat untuk melanjutkan hubungan kembali, tidak berpindah ke jasa layanan perbankan lain, niat lebih 
sering menggunakan jasa layanan perbankan syariah, harapan bisa mempertahankan hubungan lebih lama dan kuat, niat akan terus melanjutkan hubungan sekalipun ada biaya yang harus dinaikkan. Ke-enam, meliputi: merekomendasikan pada perusahaan lain untuk menggunakan pelayanan perbankan syari;ah, mengatakan hal positif tentang pelayanan perbankan syariah, mendorong perusahaan lain untuk menggunakan layanan perbankan syariah, menyesal jika tidak merekomendasikan layanan perbankan syariah pada perusahaan lain.

Pengukuran variabelnya menggunakan skala likert jenjang 5 point dengan kriteria sebagai berikut: 1 (sangat tidak setuju), 2 (tidak setuju), 3 (netral), 4 (setuju), 5 (sangat setuju)

\section{d. Sumber Data, Tehnik dan Waktu Pengumpulan Data}

Sumber data primer diperoleh dari penyebaran kuesioner, sedangkan sumber data sekunder diperoleh dari informasi tertulis tentang jenis kualitas pelayanan kepada nasabah prioritas BSM, sejarah singkat dan perkembangan perusahaan serta visi, misi BSM. Pengumpulan datanya menggunakan beberapa tehnik, yaitu: kuesioner dan observasi.

\section{e. Analisis Deskriptif}

\section{Tabel 1}

Deskripsi Responden

\begin{tabular}{llcc}
\hline Variabel & Kategori & Frekwensi & Persen \\
\hline Status Badan Hukum & Lembaga Pemerintah & 17 & $8,5 \%$ \\
\cline { 2 - 4 } Kelembagaan & Nirlaba & 74 & $37 \%$ \\
\cline { 2 - 4 } & Swasta & 109 & $54,5 \%$ \\
\hline Jumlah & & $\mathbf{2 0 0}$ & $\mathbf{1 0 0 \%}$ \\
\hline Jenis Bidang Usaha & Jasa & 97 & $48,5 \%$ \\
\cline { 2 - 4 } & Produk Barang & 103 & $51,5 \%$ \\
\hline Jumlah & & $\mathbf{2 0 0}$ & $\mathbf{1 0 0 \%}$ \\
\hline \multirow{3}{*}{ Usia Usaha } & Permanent & 34 & $17 \%$ \\
\cline { 2 - 4 } & 0-10 Tahun & 138 & $69 \%$ \\
\cline { 2 - 4 } & 11-35 Tahun & 17 & $8,5 \%$ \\
\cline { 2 - 4 } & 35 Tahun Keatas & $11,55 \%$ \\
\hline
\end{tabular}




\begin{tabular}{|c|c|c|c|}
\hline \multirow{4}{*}{$\begin{array}{l}\text { Lamanya } \\
\text { dg Bank }\end{array}$} & 0-1 tahun & 67 & $33,5 \%$ \\
\hline & $1-5$ tahun & 117 & $58,5 \%$ \\
\hline & 5-10 tahun & 16 & $8 \%$ \\
\hline & 10 tahun keatas & - & $0 \%$ \\
\hline Jumlah & & 200 & $100 \%$ \\
\hline \multirow{2}{*}{ Gender } & Laki-laki & 112 & $56 \%$ \\
\hline & Perempuan & 88 & $44 \%$ \\
\hline Jumlah & & 200 & $100 \%$ \\
\hline \multirow{3}{*}{$\begin{array}{l}\text { Umur } \\
\text { Kuesioner }\end{array}$} & 20-40 Tahun & 129 & $64,5 \%$ \\
\hline & 41-60 Tahun & 60 & $30 \%$ \\
\hline & 61 Tahun Keatas & 11 & $5,5 \%$ \\
\hline Jumlah & & 200 & $100 \%$ \\
\hline \multirow{2}{*}{$\begin{array}{l}\text { Posisi dan Peran Dalam } \\
\text { Lembaga }\end{array}$} & Kepala/Manajer & 66 & $33 \%$ \\
\hline & Karyawan/Pegawai & 134 & $67 \%$ \\
\hline Jumlah & & 200 & $100 \%$ \\
\hline
\end{tabular}

Sumber: Data Penelitian (2012)

Berdasarkan jenis transaksi elektronik perbankan yang pernah dilakukan, dari 200 responden diperoleh data dalam tabel C.2 berikut ini:

\section{Tabel 2}

\section{Jenis Transaksi Elektronik Perbankan Syariah yang Pernah Dilakukan Responden}

\begin{tabular}{lll}
\hline $\begin{array}{l}\text { Jenis } \\
\text { Perbankansaksi Elektronik }\end{array}$ & $\begin{array}{l}\text { Total Responden } \\
\mathbf{N = 2 0 0}\end{array}$ & Prosentase \\
\hline Giro & 108 & \\
\hline Tabungan & 187 & $54 \%$ \\
\hline Deposito & 84 & $93,5 \%$ \\
\hline Transfer/RTGS & 183 & $42 \%$ \\
\hline Jasa lainnya & 105 & $91,5 \%$ \\
\hline
\end{tabular}

\section{f. Pengujian Validitas dan Reliabilitas}

Uji validitas menggunakan Confirmatory Factor Analysis dengan bantuan program AMOS 6. Loading factor untuk setiap item pertanyaan harus $>0,50$ (Ghozali, 2009). Hasilnya adalah: masing-masing item kualitas tehnik, kualitas fungsional, kecocokan budaya, kepuasan, loyalitas dan rekomendasi positif dikatakan valid karena loading factor $>0,50$. Sedangkan hasil pengujian reliabilitas terhadap semua instrument di katakan reliable kareng CR $>006 \%$ 


\section{g. Uji Asumsi Model dan Normalitas Data}

Penelitian ini menggunakan 65 indikator, sehingga semua kasus yang mempunyai jarak mahalanobis lebih besar dari $\mathrm{X}^{2}$ $(65.0,001)=105,9881$ adalah multivariate outlier. Sedangkan pada penelitian ini, hasil evaluasi jarak mahalanobis menunjukkan tidak ada outlier, karena jarak mahalanobis < dari 105,9881, dan jika kita lihat lagi semakin ke bawah nilainya semakin kecil sehingga semakin membuktikan tidak adanya outlier.

Dalam uji normalitas data menunjukkan bahwa nilai dalam C.R skewness harus $>2$, sedangkan nilai yang tertera dalam penelitian ini belum terdistribusi normal secaramultivariate dengan nilai C.R kurtosis 9,354. Meskipun data belum terdistribusi secara normal namun masih termasuk dalam kategori moderat sebab C.r kurtosisnya masih < 21 (Ghozali dan Fuad, 2005).

\section{h. Uji Hipotesis}

\section{1) Analisis Kesesuaian Model (Goodness of Fit Model)}

Evaluasi nilai goodness-of-fit dari model penelitian yang diajukan, menunjukkan bahwa pada kolom CMIN, default model sebesar 2764,995 dan kolom P hasilnya 0,000 atau dibawah 0,05. Pada table CMIN/DF hasilnya sebesar 1,406 atau menunjukkan kurang dari 2. Sehingga bisa dikatakan modelnya belum fit atau belum bagus. RMR, GFI, pada kolom GFI dada tabel 4.22, default model sebesar 0,720. Karena hasilnya dibawah 0,9 maka dikatakan belum fit atau belum bagus. Secara keseluruhan pengukuran goodness of fit tersebut mengindikasikan bahwa model yang diajukan dalam penelitian ini belum dapat diterima, sehingga perlu dilakukan modifikasi model dengan cara menambah jalur (Modification Indicase) dan korelasi eror (Error Correlation) 
Tulus H, Hunik SR, Mugi H, Ekawati RN

Modifikasi model dilakukan dengan cara menambah jalur dari dimensi empathy, tangibles, reliability, compliance dan variable cultural fit pada loyalitas. Yang menjadi dasar teoritisnya adalah hasil studi Papassapa Rauyruen dan Kenneth E Miller, Markus Groth (2009) yang menunjukkan bahwa variabel persepsi kualitas pelayanan bisa berpengaruh langsung pada sikap loyal, tanpa 
melalui mediator kepuasan.

Sedangkan Pada tabel Baseline Comparison, pada kolom TLI, Rho2 sebesar 0,909 dan kolom CFI sebesar 0,914. Karena hasilnya di atas atau lebih dari 0,9 maka hasilnya di katakan baik. Hasil tersebut di katakan juga tidak sensitive terhadap sampel. Pada table RMSEA, pada kolom RMSEA diketahui hasilnya sebesar 0,045. Karena hasil tersebut kurang dari 0,08 maka dikatakan hasilnya sudah memenuhi.

\section{Tabel 3}

\section{Hasil Goodness-of-Fit Model setelah modifikasi}

\begin{tabular}{llll}
\hline Goodness of fit indices & Cut off Value & Hasil & Evaluasi Model \\
\hline Chi-Square $\left(c^{2}\right)$ & Diharapkan kecil & 1980,709 & -------- \\
\hline $\begin{array}{l}\text { Significance Probability } \\
(\mathrm{p})\end{array}$ & ${ }^{3} 0,05$ & 0,054 & Baik \\
\hline CMIN/DF & $£ 2,0$ & 1,053 & Baik \\
\hline GFI & ${ }^{3} 0,9$ & 0,791 & Marginal \\
\hline AGFI & ${ }^{3} 0,9$ & 0,762 & Marginal \\
\hline TLI & ${ }^{3} 0,9$ & 0,988 & Baik \\
\hline CFI & ${ }^{3} 0,9$ & 0,989 & Baik \\
\hline RMSEA & $£ 0,08$ & 0,016 & baik \\
\hline
\end{tabular}

Sumber: Data primer yang diolah, 2012.

\section{2) Analisis Koefisisen Jalur}

Hasil pengujian menunjukkan bahwa beberapa jalur yang dianalisis memiliki hubungan yang signifikan, yaitu terlihat dari besarnya tingkat signifikansi (p) uji hipotesis $<5 \%$ dan beberapa yang lain tidak signifikan. Analisis ini juga menunjukkan terdapat 17 jalur pengaruh langsung. Untuk pengaruh langsung, yang memiliki pengaruh paling besar adalah pengaruh kualitas tangibles pada kepuasan, yaitu sebesar 0,285. Hal ini menunjukkan bahwa kualitas tangibles memberikan pengaruh yang lebih besar secara langsung pada kepuasan dibandingkan dengan kualitas yang lain. Sedangkan jalur pengaruh tidak langsung terdapat 5 jalur.

Dari hasil pengujian SEM menunjukkan bahwa compliance, reliability, tangibles, empathy dan cultural fit bisa berpengaruh secara langsung maupun tidak langsung pada loyalitas. Kualitas 
compliance berpengaruh langsung pada loyalitas sebesar 0,227 dan pengaruh tidak langsungnya sebesar 0,007. Kualitas reliability berpengaruh langsung pada loyalitas sebesar 0,174 dan pengaruh tidak langsungnya sebesar 0,007. Kualitas tangibles berpengaruh langsung pada loyalitas sebesar 0,273 dan pengaruh tidak langsungnya sebesar 0,023. Kualitas empathy berpengaruh langsung pada loyalitas sebesar 0,282 dan pengaruh tidak langsungnya sebesar 0,006. Variabel Cultural fit berpengaruh langsung pada loyalitas sebesar 0,250 dan pengaruh tidak langsungnya sebesar 0,007. Kualitas compliance, reliability, tangibles, empathy dan variabel cultural fit pengaruh langsungnya lebih besar dari pada pengaruh tidak langsungnya pada loyalitas. Hal ini menunjukkan bahwa Kualitas compliance, reliability, tangibles, empathy dan variabel cultural fit berpengaruh langsung pada loyalitas tanpa mediasi variabel kepuasan. Hal ini mendukung hasil studi Rauyruen, P and Miller, K.E. (2009)

\section{3) Pembahasan Hipotesis}

Hasil pengujian dengan menggunakan SEM, terlihat dalam tabel 4 sebagai berikut:

\section{Tabel 4}

\section{Hasil Uji Hipotesis}

\begin{tabular}{|c|c|c|c|c|c|c|c|}
\hline & & & 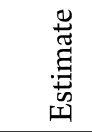 & ये & نُن & a & 鳬 \\
\hline Satisfaction & $<---$ & Culture-Fit & .160 & .056 & 2.874 & .004 & Signifikan \\
\hline Satisfaction & $<---$ & Komunikasi & .203 & .077 & 2.649 & .008 & Signifikan \\
\hline Satisfaction & $<--$ & Teknologi & -.043 & .083 & -.515 & .607 & Tidak Signifikan \\
\hline Satisfaction & $<--$ & Akses & .204 & .086 & 2.379 & .017 & Signifikan \\
\hline Satisfaction & $<--$ & Compliance & .085 & .080 & 1.065 & .287 & Tidak Signifikan \\
\hline Satisfaction & $<--$ & Assurance & -.121 & .064 & -1.884 & .060 & Tidak Signifikan \\
\hline Satisfaction & $<--$ & Reliability & .116 & .092 & 1.258 & .208 & Tidak Signifikan \\
\hline Satisfaction & $<--$ & Tangibles & .250 & .069 & 3.646 & $* * *$ & Signifikan \\
\hline Satisfaction & $<--$ & Empathy & .090 & .091 & .988 & .323 & Tidak Signifikan \\
\hline Satisfaction & $<--$ & Responsiveness & .134 & .074 & 1.814 & .070 & Tidak Signifikan \\
\hline Loyalty & $<--$ & Satisfaction & .061 & .050 & 1.223 & .221 & Tidak Signifikan \\
\hline Jumlah & & & & & & & $100 \%$ \\
\hline
\end{tabular}


Pengaruh Kualitas Pelayanan B2B Perbankan Syariah...

\begin{tabular}{llllllll}
\hline Loyalty & $<---$ & Culture-Fit & .180 & .039 & 4.651 & $* * *$ & Signifikan \\
\hline Loyalty & $<---$ & Tangibles & .182 & .047 & 3.848 & $* * *$ & Signifikan \\
\hline Loyalty & $<---$ & Reliability & .179 & .059 & 3.016 & .003 & Signifikan \\
\hline Loyalty & $<---$ & Compliance & .173 & .050 & 3.466 & $* * *$ & Signifikan \\
\hline WOM & $<---$ & Loyalty & .135 & .075 & 1.790 & .074 & Tidak Signifikan \\
\hline
\end{tabular}

Sumber: Data primer yang diolah, 2012.

H1a: persepsi kualitas pelayanan communication perbankan syariah berpengaruh signifikan pada kepuasan nasabah bisnis

Berdasarkan hasil perhitungan pada Tabel 4, didapatkan nilai C.R kualitas komunikasi pada kepuasan sebesar 2.649 dengan tingkat signifikansi 0,008 atau $\mathrm{p}<0,05$. Hasil tersebut menunjukkan bahwa hipotesis 1a didukung Artinya secara statistik dapat disimpulkan bahwa semakin bagus kualitas pelayanan komunikasi perbankan syariah akan berpengaruh positif pada kepuasan nasabah bisnis. Jika bank syariah memiliki manajer account yang khusus mengurusi nasabah bisnis, bank syariah menyediakan layanan khusus untuk mengunjungi nasabah bisnis, bank syariah menyediakan saluran komunikasi yang baik bagi nasabah bisnis dan bank syariah menggunakan simbol budaya Indonesia dalam mempromosikan produk/jasa layanannya, bank syariah juga memberikan layanan yang disesuaikan dengan kebutuhan bisnis maka nasabah bisnis akan semakin puas. Hasil penelitian ini mendukung teori Gronroos (1983; 1984) dan mendukung penelitian Guo, Duff dan Hair (2007).

H1b: Persepsi kualitas pelayanan technology perbankan syariah berpengaruh signifikan pada kepuasan nasabah bisnis

Berdasarkan hasil perhitungan pada Tabel 4 didapatkan nilai C.R kualitas komunikasi pada kepuasan sebesar -0.515 dengan tingkat signifikansi 0.607 atau p > 0,05. Hasil tersebut menunjukkan bahwa hipotesis $1 \mathrm{~b}$ tidak didukung, dan secara statistik dapat disimpulkan bahwa persepsi kualitas pelayanan komunikasi perbankan syariah tidak berpengaruh secara signifikan pada kepuasan nasabah bisnis. Hal ini dikarenakan sebagian besar 
respondennya adalah pemilik usaha dagang yang terkategori swasta atau UKM yang punya kepentingan dengan produk bank syariah, tetapi gagap teknologi. Berdasarkan data tentang Diskripsi Responden, kategori swasta sebanyak 109 dari 200 responden atau sebesar 54,5\%. Sehingga hasil penelitian ini tidak mendukung teori Gronroos $(1983$; 1984) dan tidak mendukung penelitian yang dilakukan Guo, Duff dan Hair (2007).

H1c: Persepsi kualitas pelayanan accsess perbankan syariah berpengaruh signifikan pada kepuasan nasabah bisnis

Berdasarkan hasil perhitungan pada Tabel 4 didapatkan nilai C.R kualitas komunikasi pada kepuasan sebesar 2,379 dengan tingkat signifikansi 0.017, atau p < 0,05. Hasil tersebut menunjukkan hipotesis 1c didukung, dan secara statistik disimpulkan bahwa persepsi kualitas pelayanan perbankan syariah, akan berpengaruh signifikan pada kepuasan nasabah bisnis. Jika bank syariah menyediakan kemudahan akses ke informasi akun sehingga nasabah tidak menunggu lama, bank syariah telah menyediakan layanan ATM dan e-services banking yang memadahi dibeberapa tempat/ lokasi, prosedur operasional penggunaan ATM dan e-services banking mudah dimengerti dan dijalankan, sehingga nasabah tidak menunggu lama dan bank syariah menggunakan peralatan yang canggih dan modern, maka nasabah bisnis akan semakin puas. Hasil penelitian ini mendukung teori Gronroos $(1983$; 1984) dan mendukung hasil penelitian Guo, Duff dan Hair (2007).

H2a: Persepsi kualitas pelayanan compliance perbankan syariah berpengaruh pada kepuasan nasabah bisnis

Berdasarkan hasil perhitungan pada Tabel 4 didapatkan nilai C.R compliance ada kepuasan adalah sebesar 1,065 dengan tingkat signifikansi 0.287 atau p >0,05. Hasil tersebut menunjukkan bahwa hipotesis 2a tidak didukung, dan secara statistik dapat disimpulkan bahwa persepsi kualitas kepatuhan bank syariah terhadap hukum 
Pengaruh Kualitas Pelayanan B2B Perbankan Syariah... Islam, tidak berpengaruh signifikan terhadap kepuasan nasabah bisnis. Hasil analisis ini tidak mendukung teori Gronroos (1983; 
Dan berdasarkan informasi non formal dari manajer pelayanan Bank Syariah Mandiri Cabang Kudus mengatakan bahwa sebagian besar keyakinan/agama dari para pelaku transaksi yang merupakan nasabah bisnis adalah non muslim, sehingga bisa disimpulkan ada variabel lain yang lebih mempengaruhi kepuasan. Variabel lain tersebut meliputi keamanan dalam penyimpanan dana, keamanan dan kecepatan dalam transaksi dan keuntungan berupa besarnya bagi hasil yang dijanjikan pihak perbankan syariah.

$H 2 b$ : Persepsikualitas pelayanan assurance perbankan syariah berpengaruh pada kepuasan nasabah bisnis

Berdasarkan hasil perhitungan pada Tabel 4 didapatkan nilai C.R assurance pada kepuasan adalah sebesar $-1,884$ dengan tingkat signifikansi 0.060 atau $\mathrm{p}>0,05$. Hasil tersebut menunjukkan bahwa hipotesis 2 b tidak didukung, dan secara statistik disimpulkan bahwa persepsi kualitas pelayanan assurance perbankan syariah tidak berpengaruh signifikan pada kepuasan nasabah bisnis. Hasil analisis ini tidak mendukung teori Gronroos (1983; 1984) dan tidak mendukung hasil studi Othman dan Owen (2001), karena jika dilihat dari hubungan transaksi yang dilakukan, nasabah bisnis mendapatkan pelayanan lebih istimewa dibandingkan nasabah individual (misal, diberikan ruang khusus untuk bertransaksi tanpa melalui antrian panjang di depan teller). Nasabah bisnis lebih banyak menggunakan fasilitas transaksi e banking berbasis pada teknologi informasi, sehingga mengurangi hubungan vis a vis dengan karyawan bank. Jika dilihat dari faktor budaya, masyarakat Kudus dan Pati cenderung bersifat tertutup sehingga terkesan kurang memperhatikan sifat-sifat kesopanan dan keramahan dalam konsep pelayanannya.

H2c: Persepsi kualitas pelayanan reliability perbankan syariah berpengaruh pada kepuasan nasabah bisnis

Berdasarkan hasil perhitungan pada Tabel 4 didapatkan nilai C.R Reliability pada kepuasan sebesar 1,258 dengan tingkat 


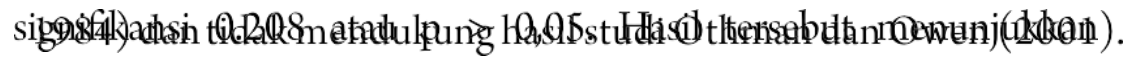

hipotesis 2c tidak didukung dan secara statistik disimpulkan bahwa persepsi kualitas pelayanan reliability perbankan syariah tidak berpengaruh signifikan pada kepuasan nasabah bisnis. Hal ini dikarenakan ada beberapa persyaratan yang sulit di penuhi nasabah bisnis ketika berhubungan dan bertransaksi dengan bank syariah terkait dengan ketentuan UU Perbankan Nasional tahun 1998 (misal: kewajiban memenuhi syarat jaminan pada saat mengajukan pembiayaan, saldo minimal yang masih tinggi di bandingkan dengan bank konvensional dan lamanya waktu untuk transaksi kliring dengan bank lain. Hasil analisis ini tidak mendukung teori Gronroos $(1983$; 1984) dan tidak mendukung hasil studi Othman dan Owen (2001).

H2d: Persepsi kualitas pelayanan tangibles perbankan syariah berpengaruh pada kepuasan nasabah bisnis

Berdasarkan hasil perhitungan pada Tabel 4 didapatkan nilai C.R Tangibles pada kepuasan sebesar 3,646 dengan tingkat signifikansi 0,000 atau $\mathrm{p}<0,05$. Hasil tersebut menunjukkan bahwa hipotesis $2 \mathrm{~d}$ didukung, dan secara statistik dapat disimpulkan persepsi kualitas pelayanan tangibles perbankan syariah berpengaruh signifikan pada kepuasan nasabah bisnis. Hal in dikarenakan penampilan eksternal staf bank syariaah bagus, terukur dan modern, fasilitas fisiknya selalu memikat dan memiliki daya tarik visual, selalu mengutamakan kecepatan dan efisiensi dalam bertransaksi, jam buka operasional bank tepat waktu, ada counter partisi di bank dan cabang-cabangnya, dan ada hak istimewa pada saat account nasabah berjalan, sehingga nasabah semakin puas. Hasil analisis ini mendukung teori Gronroos (1983; 1984) dan mendukung hasil studi Othman dan Owen (2001).

H2e: Persepsi kualitas pelayanan empathy perbankan syariah berpengaruh pada kepuasan nasabah $B 2 B$

Berdasarkan hasil perhitungan pada Tabel 4 didapatkan nilai C.R Empathy pada kepuasan sebesar 0,988 dengan tingkat signifikansi 0,323 atau $\mathrm{p}>0,05$. Hasil tersebut menunjukkan bahwa 
bahwa persepi kualitas pelayanan empathy perbankan syariah, tidak berpengaruh signifikan pada kepuasan nasabah bisnis. Hipotesis ini tidak didukung, karena terkait dengan lokasi Bank Syariah Mandiri Cabang Kudus dan Pati yang hanya satu di masing-masing Kabupaten dan lokasinya terdapat di pusat kota, sehingga yang berada di wilayah pelosok tidak bisa mengakses layanan bank syariah. Layanan dan tempat parkir Bank Syariah Mandiri Cabang Kudus dan Pati tidak memadai dan sangat sempit, sehingga mempengaruhi jawaban responden terhadap dimensi responsiveness. Hasil analisis ini tidak mendukung teori Gronroos (1983; 1984) dan tidak mendukung hasil studi Othman dan Owen (2001).

H2f: Persepsi kualitas pelayanan Responsiveness perbankan syariah berpengaruh pada kepuasan nasabah bisnis

Berdasarkan hasil perhitungan pada Tabel 4 didapatkan nilai C.R responsiveness pada kepuasan sebesar 1,814 dengan tingkat signifikansi 0,070 atau $\mathrm{p}>0,05$. Hasil tersebut menunjukkan hipotesis $2 \mathrm{f}$ tidak didukung, dan secara statistik disimpulkan bahwa persepsi kualitas pelayanan responsiveness perbankan syariah tidak berpengaruh signifikan pada kepuasan nasabah bisnis. Hipotesis ini tidak di dukung dikarenakan beberapa responden masih merasakan adanya pelayanan yang kurang cepat dikarenakan tidak adanya karyawan tambahan (misal: tambahan tenaga teller) yang membantu pada saat transaksi baik penyimpanan maupun penarikan dana. Hasil analisis ini tidak mendukung teori Gronroos (1983; 1984) dan tidak mendukung hasil studi Othman dan Owen (2001).

H3: Variabel cultural fit berpengaruh pada kepuasan nasabah bisnis

Berdasarkan hasil perhitungan pada Tabel 4 didapatkan nilai C.R Kecocokan Budaya pada kepuasan sebesar 2,874 dengan tingkat signifikansi 0,004 atau $\mathrm{p}<0,05$. Hasil tersebut menunjukkan 


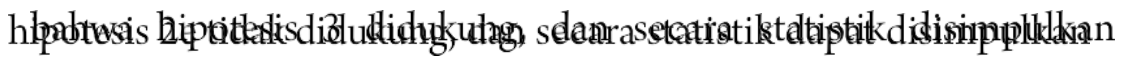
bahwa cultural fit nasabah bisnis berpengaruh signifikan terhadap kepuasan. Pada saat nasabah bisnis merasa memiliki hubungan personal dan koneksi yang baik dengan bank/staf bank syariah, mampu berkomunikasi vis a vis dalam proses membangun kepercayaan dengan perbankan syariah, memiliki tujuan yang jelas dan terukur dalam berhubungan dengan perbankan syariah, mampu mengendalikan resiko jika terjadi kegagalan hubungan dan bisa beradaptasi dengan menggunakan kualitas layanan B2B perbankan syariah yang berbasis pada teknologi informasi dan berbahasa Inggris, maka nasabah bisnis akan semakin puas. Hasil penelitian ini mendukung teori budaya Hofstede (1991) dan hasil studi empiris sebagaimana yang dilakukan Vatanasakdakul, Ramburuth, Dambra 2010

H4: Semakin tinggi tingkat kepuasan berpengaruh positif pada loyalitas nasabah bisnis

Berdasarkan hasil perhitungan pada Tabel 4 didapatkan nilai C.R kepuasan pada loyalitas sebesar 1,223 dengan tingkat signifikansi 0,221 atau $\mathrm{p}>0,05$. Hasil tersebut menunjukkan hipotesis 4 tidak didukung, dan secara statistik dapat disimpulkan bahwa semakin tinggi tingkat kepuasan tidak berpengaruh signifikan pada loyalitas nasabah bisnis atau variable kepuasan belum tentu menjadi variabel mediasi antara kualitas pelayanan B2B terhadap loyalitas. Hasil analisis ini tidak mendukung studi Caceres dan Paparoidamis (2005) yang menyatakan bahwa kepuasan menjadi variabel mediator antara kualitas pelayanan dengan loyalitas, sebaliknya penelitian ini mendukung studi Rauyruen dan K.E Miller, M. Groth (2009).

H5: Semakin tinggi tingkat loyalitas nasabah bisnis berpengaruh positif pada rekomendasi positif

Berdasarkan hasil perhitungan pada Tabel 3.5 didapatkan nilai C.R loyalitas pada rekomendasi positif sebesar 1,790 dengan tingkat signifikansi 0,074 atau p > 0,05. Hasil tersebut menunjukkan hipotesis 5 tidak didukung, dan secara statistik disimpulkan bahwa 
rekomendasi positif nasabah bisnis. Hipotesis 5 tidak di dukung karena kurangnya pemahaman nasabah bisnis terhadap layanan purna transaksi di BSM Cabang Kudus dan Pati sehingga mampu meningkatkan loyalitas dan rekomendasi positif nasabah bisnis. Hal ini di dukung oleh sifat dan karakter nasabah bisnis yang cenderung individual karena berhubungan dengan perbankan syariah hanya untuk kepentingan organisasi atau perusahaan saja. Hasil penelitian ini tidak mendukung penelitian yang dilakukan oleh Thurau et al (2002).

\section{i. Pembahasan Sub Hipotesis}

Berdasarkan hasil analisis uji koefisien jalur, ketika terjadi penambahan jalur didapatkan hasil, dimensi empathy, tangibles, reliability, compliance dan variable cultural fit bisa berpengaruh langsung maupun tidak langsung terhadap loyalitas. Dari hasil uji hipotesis sebagaimana terdapat dalam 4 diketahui bahwa nilai C.R empathy pada loyalty sebesar 4,146 dengan tingkat signifikansi sebesar 0,000 atau $\mathrm{p}<0,05$. Hasil ini menunjukkan bahwa semakin baik kualitas empathy akan berpengaruh langsung dan signifikan pada loyalitas. Nilai C.R tangibles pada loyalty sebesar 4,651 dengan tingkat signifikansi sebesar 0,000 atau p <0,05. Hasil ini menunjukkan bahwa semakin baik kualitas tangibles akan berpengaruh langsung dan signifikan pada loyalitas. Nilai C.R reliability pada loyalty sebesar 3,016 dengan tingkat signifikansi sebesar 0,003 atau $\mathrm{p}<$ 0,05 . Hasil ini menunjukkan bahwa semakin baik kualitas reliability akan berpengaruh langsung dan signifikan pada loyalitas. Nilai C.R compliance pada loyalty sebesar 3,466 dengan tingkat signifikansi sebesar 0,000 atau $\mathrm{p}<0,05$. Hasil ini menunjukkan bahwa semakin baik kualitas compliance akan berpengaruh langsung dan signifikan pada loyalitas. Nilai C.R variabel cultural fit pada loyalty sebesar 4,651 dengan tingkat signifikansi sebesar 0,000 atau $p<0,05$. Hasil ini menunjukkan bahwa semakin tinggi tingkat cultural fit nasabah bisnis akan berpengaruh langsung dan signifikan pada loyalitas.

Pada tahap penambahan jalur inilah, ditemukan beberapa 


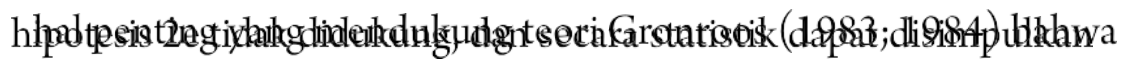
tujuan model PerServQual Gronroos (1983; 1984) tidak pernah dimaksudkan untuk menjadi satu-satunya operasional model kualitas pelayanan, tetapi dikembangkan dan diperkenalkan sebagai bangunan teori yang membantu akademisi dan praktisi untuk memahami sifat yang hilang dari produk perusahaan jasa, yaitu untuk memahami proses layanan itu sendiri sebagai solusi untuk masalah pelanggan sebagai tujuan utama dari pemasaran dan dalam rangka untuk mengembangkan konsistensi agar berfungsi sebagai alat pemasaran yang baik bagi penyedia layanan (bagaimana kualitas layanan yang dirasakan oleh pelanggan diharapkan akan diukur dengan menggunakan pendekatan kepuasan pelanggan). Hal ini memperjelas bahwa evaluasi proses kualitas pelayanan sangatlah kompleks karena beroperasi pada berbagai tingkatan yang abstrak dan kualitas jasa merupakan konsep industri yang spesifik (Gronroos, 1983; 1984).

Penelitian juga mendukung hasil studi terdahulu yang dilakukan Rauyruen, P and Miller, K.E. (2009) yang menunjukkan bahwa variabel persepsi kualitas pelayanan bisa berpengaruh langsung pada sikap loyal, tanpa melalui mediator kepuasan tetapi tidak mendukung hasil studi terdahulu yang dilakukan oleh Ceceras and Paparoidamis (2005) yang menyatakan bahwa variabel kepuasan menjadi variabel mediator antara kualitas pelayanan dengan loyalitas.

\section{Simpulan}

Berdasarkan analisis data dan pembahasan mengenai analisis pengaruh kualitas pelayanan B2B perbankan syariah, kecocokan budaya, kepuasan, loyalitas dan rekomendasi positif, maka dapat dikemukakan beberapa kesimpulan dan rekomendasi sebagai berikut. Persepsi kualitas pelayanan komunikasi perbankan syariah, akan berpengaruh positif pada kepuasan nasabah bisnis. Persepsi kualitas pelayanan komunikasi perbankan syariah tidak berpengaruh secara signifikan pada kepuasan nasabah bisnis. Persepsi kualitas pelayanan assurance, reliability, emphaty and 
responsiveness perbankan syariah, tidak berpengaruh signifikan pada kepuasan nasabah bisnis. Persepsi kualitas pelayanan tangibles dan kecocokan budaya perbankan syariah, akan berpengaruh signifikan pada kepuasan nasabah bisnis. 


\section{DAFTAR PUSTAKA}

Antonio, S.M. (2001). Bank Syariah Dari Teori ke Praktek. Jakarta: Gema Insani Press.

Avkiran, N.K. (1994). Developing an instrument to measure customer service quality in branch banking International Journal of Bank Marketing, Vol. 12 No. 6.

Babakus, E. and Boller, G.W. 1992. An empirical assessment of the SERVQUAL scale Journal of Business Research, Vol. 24.

Bahia, K. and Nantel, J. (2000). A reliable and valid measurement scale for the perceived service quality of banks International Journal of Bank Marketing, Vol. 18 No. 2.

Caceras, R.C and Paparoidamis, N.G. (2005). Service Quality, Relationship, Satisfaction, Trust, Commitment and Bussiness-to-Bussiness Loyalty. European Journal of Marketing, Vol.41 No. 7/8.

Direktorat Perbankan Syariah. (2012). Bank Indonesia, Statistik Perbankan Syariah - Januari 2012, dari WWW.bi.go.id, diunduh 9 Februari 2013.

Direktorat Perbankan Syariah. (2013). Bank Indonesia, Outlook Perbankan Syariah Th. 2013, dari WWW.bi.go.id, diunduh 9 Februari 2013.

Ferdinand, A. (2006). Metode Penelitian manajemen: Pedoman Penelitian untuk Penulisan Skripsi, Tesis dan Disertasi Ilmu manajemen, Semarang: Badan Penerbit Universitas Diponegoro.

Gounaris, S.P. and Venetis, K. (2002). Trust in industrial service relationships: behavioral consequences, antecedents and the moderating effect of the duration of the relationship The Journal of Services Marketing. Vol. 16 No. 7.

Guo, X, Duff. A, Hair, M. (2008). Service quality measurement in the Chinese corporate banking market , International. Journal of Bank Marketing Vol. 26 No. 5. 
Gro"nroos, C.. (1983). Strategic Management and Marketing in the Service Sector. Marketing Science Institute, Cambridge, MA.

Gro"nroos, C. (1984). A service quality model and its marketing implications. European Journal of Marketing, Vol. 18.

Gro"nroos, C.. (1990). Service Management and Marketing: Managing the Moments of Truth in Service Competition. Free Press/Lexington Books, New York, NY.

Harian Republika. 21/1/2011.

Hofstede, G. (1984). Cultures Consequences: International Differences in Woek-relate Values. Sage Publication. Beverly Hills.

Kotler, P. (2004). Manajemen Pemasaran Jilid I. Jakarta: PT Indeks Kel Gramedia.

Lassar, W.M., Manolis, C. and Lassar, S.S. (2005). The relationship between consumer innovativeness, personal characteristics, and online banking adoption, International Journal of Bank Marketing;, Vol. 23 No. 2.

Lewis. R.g, dan Smith. D.H. (1994). Total Quality in Higer Education. Delray Beach, Florida: St. Lucie Press.

Majalah Sharing. (2009). Tim Penelitian dan Pengembangan Sharing, Sejarah Perkembangan Ekonomi Syariah di Indonesia, Edisi 34 Tahun IV Oktober 2009.

Majalah Sharing. (2011). Tim Penelitian dan Pengembangan Sharing.

Menggagas Bisnis H+. Edisi 50 Tahun V Februari 2011.

Morgan, Robert M. and Shelby D. Hunt. (1994).

Trust Theory of Relationship Marketing. Journal of Marketing. Vol. 58, No. 7 .

Oliver, R.L. (1999). Whence consumer loyalty.Journal of Marketing. Vol. 63.

Othman, A. and Owen L. (2001). Developing an Instrument to measure customer service quality (SQ) in Islamic banking. International Journal of Islamic Financial Services, Vol. 3, 
N0.1.

Parasuraman, A., Zeitham, A.V. and Berry, L.L. (1985). A Conceptual model of service quality and its implication for future research. Journal of Marketing; Vol. 49 No.4.

Parasuraman, A., Zethaml. A.V, and Berry. L.L.. (1985). A Conceptual Model of Service Quality. Journal of Retailing. Vol. 67.

Rauyruen, P and Miller, K.E. (2009). B2B services: linking service loyalty and brand Equity. Journal of Services Marketing. Vol. 23, No. 3 .

Saunders, S.G., Bendixen, M., Abratt, R. (2007). Banking patronage motives of the urban informal poo. Journal of Services Marketing, Vol. 21, No. 1.

Shellhase, R., Hardock, P. and Ohlwein, M. (1999). Customer satisfaction in business to-business marketing: the case of retail organizations and their suppliers, Journal of Business \& Industrial Marketing, Vol. 14 Nos 5.

Vatanasakdakul, S., Dambra, J., Ramburuth, P. (2010). IT Doesnt Fit! The Influence of Culture on B2B in Thailand. Journal of Global Information Technology Management, Vol 13. No. 3.

Ventakraman, N. (1989). The Concept of Fit in Strategy Research: Toward Verbal and Statistical Correspondence. Academy of Management Review.

Wallace, David W., Joan L. Giese and Jean L. Johnson. (2004). Customer Retailer Loyalty in the Context of Multiple Channel Strategies. Journal of Retailing, Vol. 80. No. 4.

Woo, K.S. and Ennew, C.T. (2005). Measuring business-to-business professional service quality and its consequence. Journal of Business Research, Vol. 58 No. 9.

Zeithaml. A.V, Berry.L.L, and Parasuraman. (1990). Communication and Control Process in the Delivary of Service Quality. Journal of Marketing. Vol. 52. 